\title{
Digital Detection of Genetic Mutations Using SPC-Sequencing
}

\author{
Hameer Ruparel, ${ }^{1,2}$ Michael E. Ulz, ${ }^{1}$ Sobin Kim, ${ }^{1,2}$ and Jingyue Ju ${ }^{1,2,3}$ \\ ${ }^{1}$ Laboratory of DNA Sequencing and Chemical Biology, Columbia Genome Center, Columbia University College of Physicians and \\ Surgeons, New York, New York 10032, USA; ${ }^{2}$ Department of Chemical Engineering, Columbia University, \\ New York, New York 10027, USA
}

\begin{abstract}
Deletion or insertion mutations lead to a frameshift that causes misalignment between wild-type and mutated allele sequences, making it difficult to identify such mutations unambiguously by using electrophoresis-based DNA sequencing. We have previously established the feasibility of an accurate DNA sequencing method using solid-phase capturable (SPC) dideoxynucleotides and MALDI-TOF mass spectrometry on synthetic templates, an approach we refer to as SPC-sequencing. Here, we report the application of SPC-sequencing in characterizing frameshift mutations by using the detection of the BRCAl gene mutations 185delAG and 5382insC as examples. In this method, Sanger DNA sequencing fragments are generated in one tube by using biotinylated dideoxynucleotides. The sequencing fragments carrying a biotin moiety at the $3^{\prime}$ end are captured on a streptavidin-coated solid phase to eliminate excess primer, primer dimers, and false stops. Only correctly terminated DNA fragments are captured, subsequently released, and analyzed by mass spectrometry to obtain digital DNA sequencing data. This method produces distinct doublet mass peaks at each point in the mass spectrum beyond the mutation site, facilitating the accurate characterization of the mutation. We have compared SPC-sequencing with electrophoresis-based sequencing in characterizing the above $B R C A 1$ mutations, demonstrating the significant advantage offered by SPC-sequencing for the accurate identification of frameshift mutations.
\end{abstract}

With the completion of the Human Genome Project, many recent advances in genome technology have been focused on the analysis and characterization of genetic variations. The study of genetic mutations has applications in many areas of biological and medical research, including pharmacogenomics (Roses 2000; Pirmohamed and Park 2001), disease gene discovery and gene function studies (Friedman et al. 1994; Stickney et al. 2002), forensic analysis (Reynolds et al. 1991), and evolution studies (Kyriacou 2002). Many techniques have therefore been investigated for the robust and efficient analysis of mutations. Traditionally used indirect methods such as single-strand conformation polymorphism, denaturing gradient gel electrophoresis, and heteroduplex analysis are simple, rapid, and efficient mutationscreening tools (Tchernitchko et al. 1999; Kourkine et al. 2002; Andersen et al. 2003) but cannot be used to accurately characterize the nature of the mutation.

Common genetic mutations may be broadly classified as point mutations such as substitutions or frameshift mutations caused by insertions or deletions. Single base extension (SBE) has been widely used to detect point mutations. This technique, involving the extension of a primer by only one base using a single dideoxynucleotide terminator, has been very effective in the successful characterization of single nucleotide polymorphisms (SNPs; Chen et al. 1997; Fei et al. 1998; Ross et al. 1998; Li et al. 1999; Kim et al. 2002). However, using this method, it might be difficult to distinguish between point mutations and deletions or insertions that occur frequently at various loci throughout the genome.

Direct DNA sequencing, in theory, is the most accurate technique for mutation detection because it can successfully identify and characterize most sequence variations. In this category, Sanger DNA sequencing using capillary array electrophoresis

\section{${ }^{3}$ Corresponding author.}

E-MAIL dj222@columbia.edu; FAX (212) 851-5215.

Article and publication are at http://www.genome.org/cgi/doi/10.1101/ gr.1344104. with laser-induced fluorescence detection (Smith et al. 1986; Prober et al. 1987; Huang et al. 1992; Ju et al. 1995) is the current state-of-the-art sequencing technology that has been used to sequence the human genome. However, this technique faces difficulties in detecting heterozygous nucleotide variations and in accurately sequencing GC-rich regions due to the compression of the DNA fragments during electrophoretic separation (Bowling et al. 1991). Pyrosequencing is an alternative sequencing approach, in which each nucleotide is identified as soon as it has been incorporated by DNA polymerase in a growing DNA strand (Ronaghi et al. 1998). Over the past few years, this approach has been successfully used to characterize short DNA sequences. Although this approach is now widely used for detecting SNPs and other DNA variations, it faces difficulties in accurately sequencing homopolymeric regions in DNA (Fakhrai-Rad et al. 2002). Furthermore, both of the above DNA sequencing methods have problems characterizing frameshift mutations, because a deletion or insertion in any one allele will cause the sequencing reaction between the two alleles to be out of phase, leading to difficulties in interpreting the sequencing data.

Recently, matrix-assisted laser desorption/ionization timeof-flight mass spectrometry (MALDI-TOF MS) has been used as an analytical tool for DNA sequencing (Roskey et al. 1996; Fu et al. 1998; Kirpekar et al. 1998; Taranenko et al. 1998; Kaetzke and Eschrich 2002). We have developed a MALDI-TOF MS DNA sequencing method that generates Sanger sequencing fragments in one tube using solid-phase capturable (SPC) biotinylated dideoxynucleotides (Edwards et al. 2001), a method we refer to as SPC-sequencing. The DNA sequencing fragments that carry a biotin at the 3' end are made free of salts and other components in the sequencing reaction by capturing them with streptavidincoated magnetic beads. Only correctly terminated biotinylated DNA fragments are subsequently released and analyzed by MS to obtain accurate DNA sequencing data. We have previously shown that this method produces clean accurate sequencing data on synthetic DNA templates. Here, we report the use of SPC- 
sequencing to accurately detect and characterize frameshift mutations in PCR-amplified templates from genomic DNA without experiencing the limitations of all the above-mentioned mutation-detection techniques. In particular, we characterized the $185 \mathrm{del} A G$ and 5382ins C mutations in the BRCA1 gene commonly occurring in members of the Ashkenazi population with a strong family history of breast and ovarian cancer (Friedman et al. 1994). Comparison of SPC-sequencing with electrophoresisbased fluorescent sequencing using the same DNA template indicates that the SPC-sequencing method is superior for detecting frameshift mutations with digital data output.

\section{RESULTS AND DISCUSSION}

The principal advantage of SPC-sequencing using biotinylated dideoxynucleotide terminators and MALDI-TOF MS for mutation detection is the highly accurate identification of different bases coexisting at a single position in the DNA, which is a direct consequence of the presence of substitution or frameshift mutations. MALDI-TOF MS analysis displays the sequence data in the form of distinct digital mass peaks. This facilitates a more accurate characterization of frameshift mutations compared with that of other sequencing methods that measure fluorescent or radioactive signals emitted from the labeled DNA.

A schematic representation of the SPC-sequencing method for the digital detection of DNA sequences is shown in Figure 1. A wild-type DNA molecule has both copies bearing identical bases at every position in the sequence. Therefore, a mass spectrum resulting from a sequencing reaction from such a template will have a single peak at each position that will yield the identity of the base at that position (Fig. 1, left). However, in the case of a DNA molecule bearing a deletion or insertion in one of its copies, the two alleles will have a relative frameshift between them following the mutation site. Therefore, each position in the DNA sequence after the mutation site may be occupied by two different bases. With SPC-sequencing, every position before the mutation site will show single peaks, as observed in the wild-type data, whereas every position beyond the mutation site will have two distinct peaks corresponding to the masses of the two nucleotides present at that position (Fig. 1, right). By calculating the differences in masses between subsequent peaks, the sequences of the two alleles can be read simultaneously and the mutation site can be unambiguously identified.

We used the SPC-sequencing method to characterize the 185delAG and 5382ins C loci in DNA from donors that were known to have the two characteristic BRCA1 mutations, and we compared the results to those obtained by using electrophoresisbased DNA sequencing. The capillary electrophoresis sequencing results for the 185delAG locus are shown in Figure 2A. It can be seen that the sequencing data is clean and well-resolved up to the " $\mathrm{T}$ " at position 217, after which the sequencing data become noisy and the sequences assigned by the basecaller are no longer accurate. This phenomenon can be explained by the fact that the existence of a frameshift mutation in one of the two DNA copies in that region causes misalignment between the sequences of the two alleles. Therefore, beyond the mutation site, there are two different sequences superimposed on each other, causing the fluorescence signals to be unresolvable. It might be possible to confirm the presence of a mutation by recognizing this distinct pattern in the sequencing data for a mutant in a combination with sequencing data from the reverse direction, but an accurate characterization of the mutation from these data might still prove difficult and tedious. Figure $2 \mathrm{~B}$ shows the SPC-sequencing results for the same region around the 185delAG mutation site. The first position in the spectrum is occupied by a single large peak corresponding to a " $\mathrm{T}$ " in both alleles. This is followed by a doublet peak at the second position in the spectrum, which identifies this position as the mutation site. The subtraction of the mass of the previous " $\mathrm{T}$ " peak from the masses of these two peaks establishes their identities as $C$ and A. Similarly, the identities of the two peaks at the next position are confirmed as $\mathrm{T}$ and $\mathrm{A}$, and in this manner, the identities of the nucleotides at all subsequent

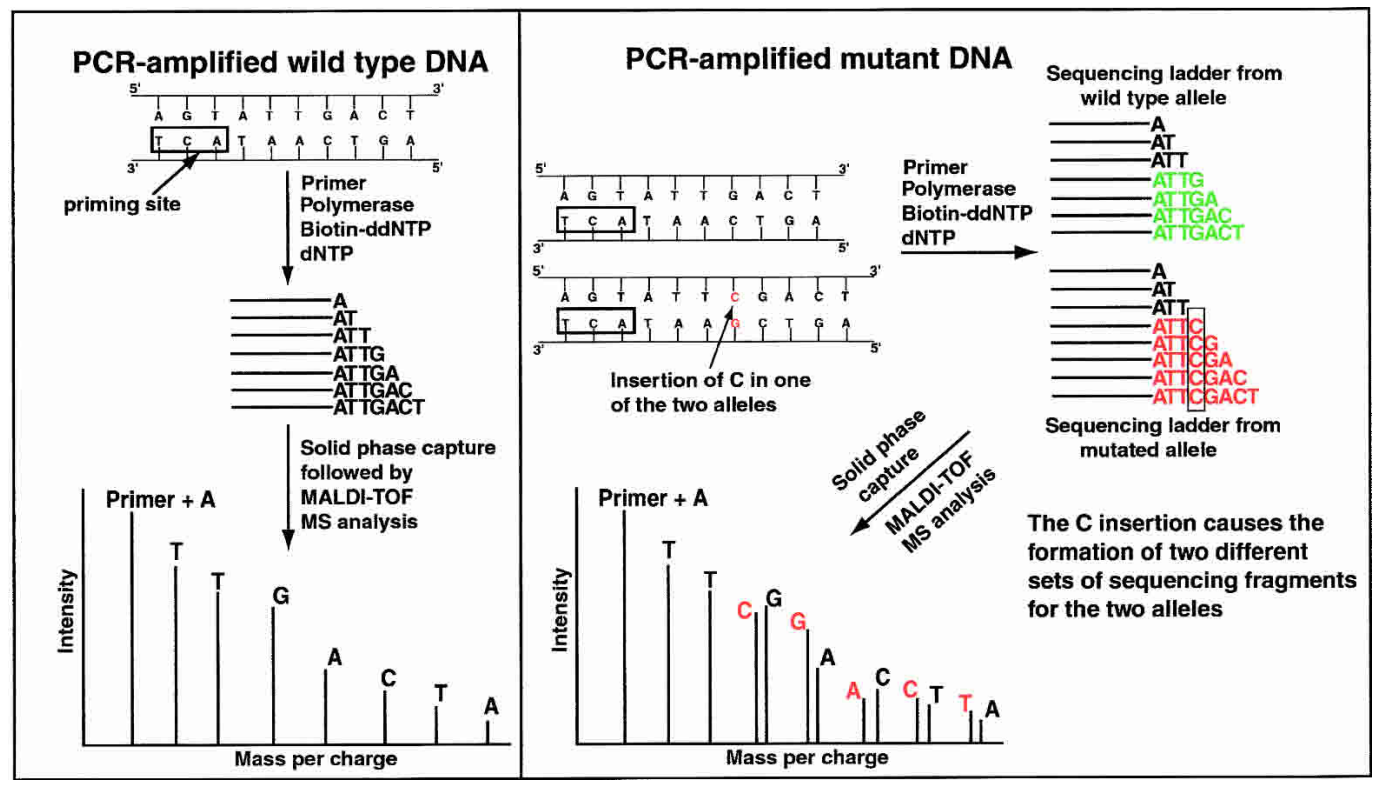

Figure 1 Schematic representation of mutation detection using solid-phase capturable dideoxynucleotide terminators and MALDI-TOF MS. Wild-type DNA has the same sequence for both copies, from which a single peak is produced at every position in the mass spectrum that corresponds to the nucleotide existing at that position in the DNA template (left). However, mutant DNA with an insertion or deletion (insertion shown here as an example) in one copy can have two different bases coexisting at the same sequence position in the two alleles. This leads to the formation of two distinct mass peaks at each position in the mass spectrum (right). By calculating the corresponding mass differences, the sequences of both alleles can be simultaneously read and the mutation site can be accurately characterized. 


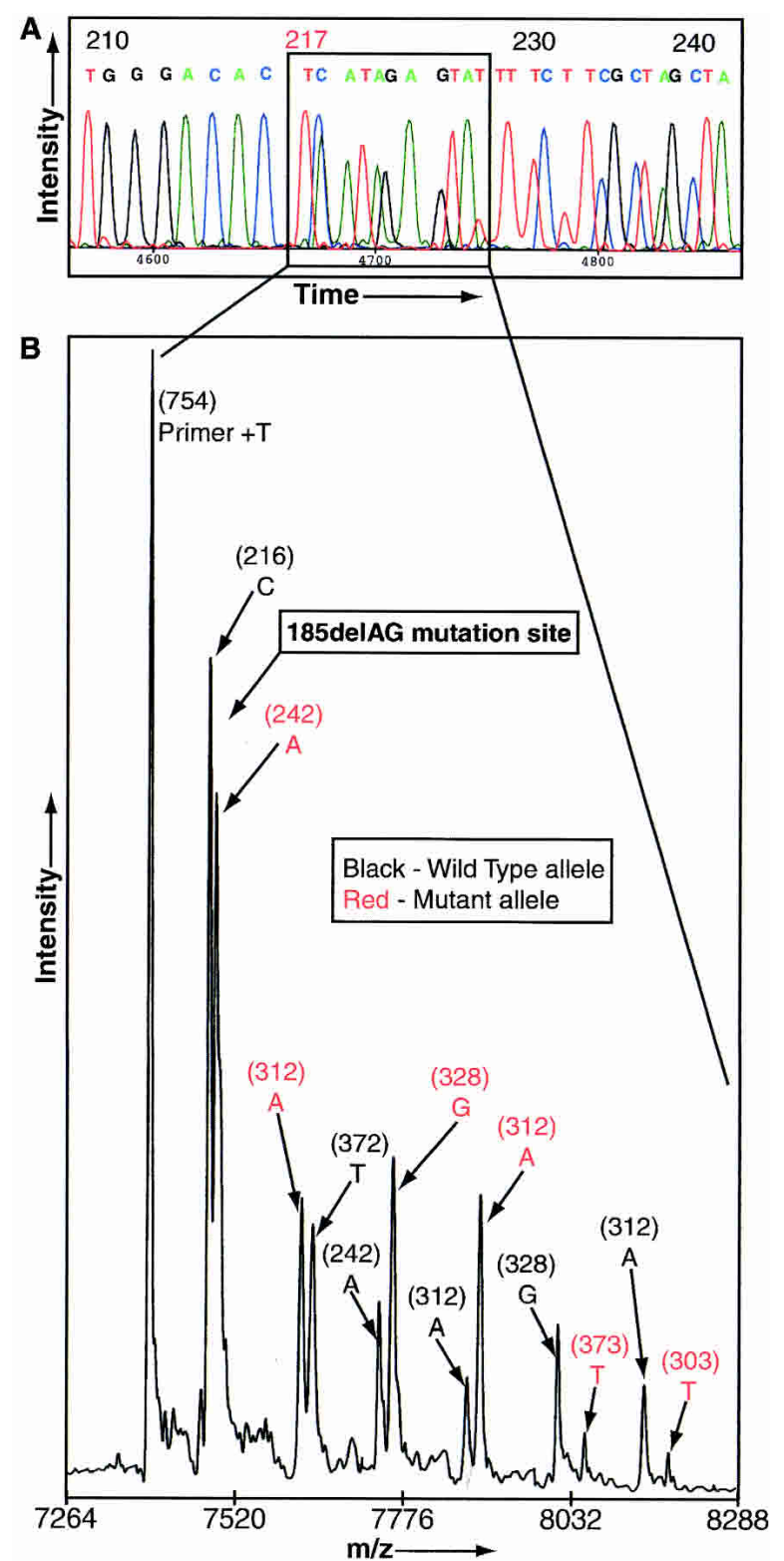

Figure 2 (A) Sequence electropherogram for the 185delAG mutant. Peaks are clear before the mutation site and ambiguous beyond the mutation site (after " $T$ " at position 217). (B) Mass spectrum showing the sequencing data for a $185 \mathrm{del} A \mathrm{G}$ mutant. The first single peak corresponds to $\mathrm{a}$ " $\mathrm{T}$ " in both alleles, showing there is no mutation up to that point. The deletion of a $C$ and $T$ in one of the two copies ( $A$ and $G$ in the forward sequence) in the subsequent two positions causes the appearance of a series of double peaks starting from the second position. The reverse wild-type DNA sequence is $3^{\prime}$ - . . . TCTAAGA . . . 5', whereas the mutant DNA sequence is $3^{\prime}-\ldots$ TAAGATT . . - $-5^{\prime}$.

positions in the mass spectrum can be established. Consequently, the two sequences identified from the spectrum are 3 'TCTAAGA . . . -5' and 3'-TAAGATT ...-5'. The wild-type sequence in this region is known to be $3^{\prime}-\ldots$ TCTAAGATTT . . . - -5'. Thus, after comparing the two parallel sequences obtained in the mass spectrum to the known wild-type sequence, it can be unequivocally confirmed that there is a deletion of a $\mathrm{C}$ and a $\mathrm{T}$ after the first " $\mathrm{T}$ " in one of the alleles. These data therefore confirm that the SPC-sequencing method identifies deletions accurately.

The data in Figure 3 demonstrate the efficacy of the SPC- sequencing method in characterizing insertion mutations. The capillary electrophoresis sequencing results for the 5382ins $C$ locus are shown in Figure 3A. As observed similarly in Figure 2A, the data are unintelligible beyond a particular position (" $\mathrm{C}$ " at 118 ) in the fluorescence electropherogram. This phenomenon is again explained by the presence of a frameshift mutation (insertion of a "C"), which causes the sequences of the two alleles to go out of phase with each other, rendering the sequence unreadable beyond the mutation site. Figure 3B shows the SPC-sequencing results for the same region around the 5382ins $C$ mutation site. After performing a similar analysis as for the 185delAG locus described above, the sequences of the two alleles in this region were identified as $5^{\prime}-\ldots$ CCAGGA ...- $-3^{\prime}$ and $5^{\prime}-\ldots$ CCCAGG . . . $-3^{\prime}$. The wild-type sequence is known to be $5^{\prime}$ - . . CCAGGA . . . - $3^{\prime}$. Thus, comparing the two sequences to the known wild-type sequence, it is straightforward to conclude that there is an insertion of a " $\mathrm{C}$ " in one of the two alleles.

These results show that SPC-sequencing using biotinylated dideoxynucleotides and MALDI-TOF MS is highly accurate in characterizing frameshift mutations. The data acquisition is very rapid, and the sequencing results are clear and easily interpreted. The electrophoresis-based sequencing method, which uses fluorescence detection, often experiences masking of the first few bases by the high-intensity fluorescence signals from the labeled primers or terminators. Thus, the sequencing primers must be designed a few bases away from the mutation site of interest in order to obtain coherent sequencing data for that region. However, the SPC-sequencing method does not face this limitation, because the data are obtained in the form of a mass spectrum with no false signals. Consequently, the sequencing primers can be designed very close to the mutation site, and thus, very few bases need to be sequenced to successfully characterize the mutation. This makes the SPC-sequencing method desirable for mutation analysis, despite the read length being currently limited to $<100 \mathrm{bp}$. With electrophoresis-based fluorescent DNA sequencing methods, the identification of deletions and insertions requires that the sequence data be manually analyzed. In this regard, a significant advantage offered by SPC-sequencing is the potential automation of data analysis facilitated by the digital data output. When using conventional ddNTPs, the smallest mass difference between any two ddNTPs is $9 \mathrm{Da}$ (between A and T), which is difficult to resolve by MALDI-TOF MS (Fei et al. 1998). In the SPC-sequencing method using biotinylated ddNTPs, the difference between $\mathrm{A}$ and $\mathrm{T}$ is increased to $66 \mathrm{Da}$, whereas the smallest mass difference among the possible DNA sequencing products is $16 \mathrm{Da}$ (between biotin-11-ddATP and biotin-11-ddGTP), which is large enough to be well-resolved in the mass spectrum. Furthermore, because the data are in the form of distinct mass peaks, one can assign bases to each peak by doing simple mathematical calculations. This eliminates the requirement of lengthy base-calling algorithms, which are a necessity in fluorescence-based DNA sequencing methods due to the broad emission spectra from the fluorophores.

The Ashkenazi BRCA1 mutations described here are but one example of a multitude of frameshift mutations that exist genomewide and can have a significant contribution to the development of diseases. For example, mutations in the $p 53$ gene play a major role in the development of many cancers (Steele et al. 1998). Therefore, with further development in automation and sample processing, the SPC-sequencing mutation-detection method can serve as a robust, efficient, and accurate tool for screening known mutations, with vast applications in clinical diagnostics. Furthermore, mutations that are as yet uncharacterized can also be accurately identified by using the SPCsequencing method in combination with the fluorescent Sanger DNA sequencing method. Thus, our future efforts are directed 
A

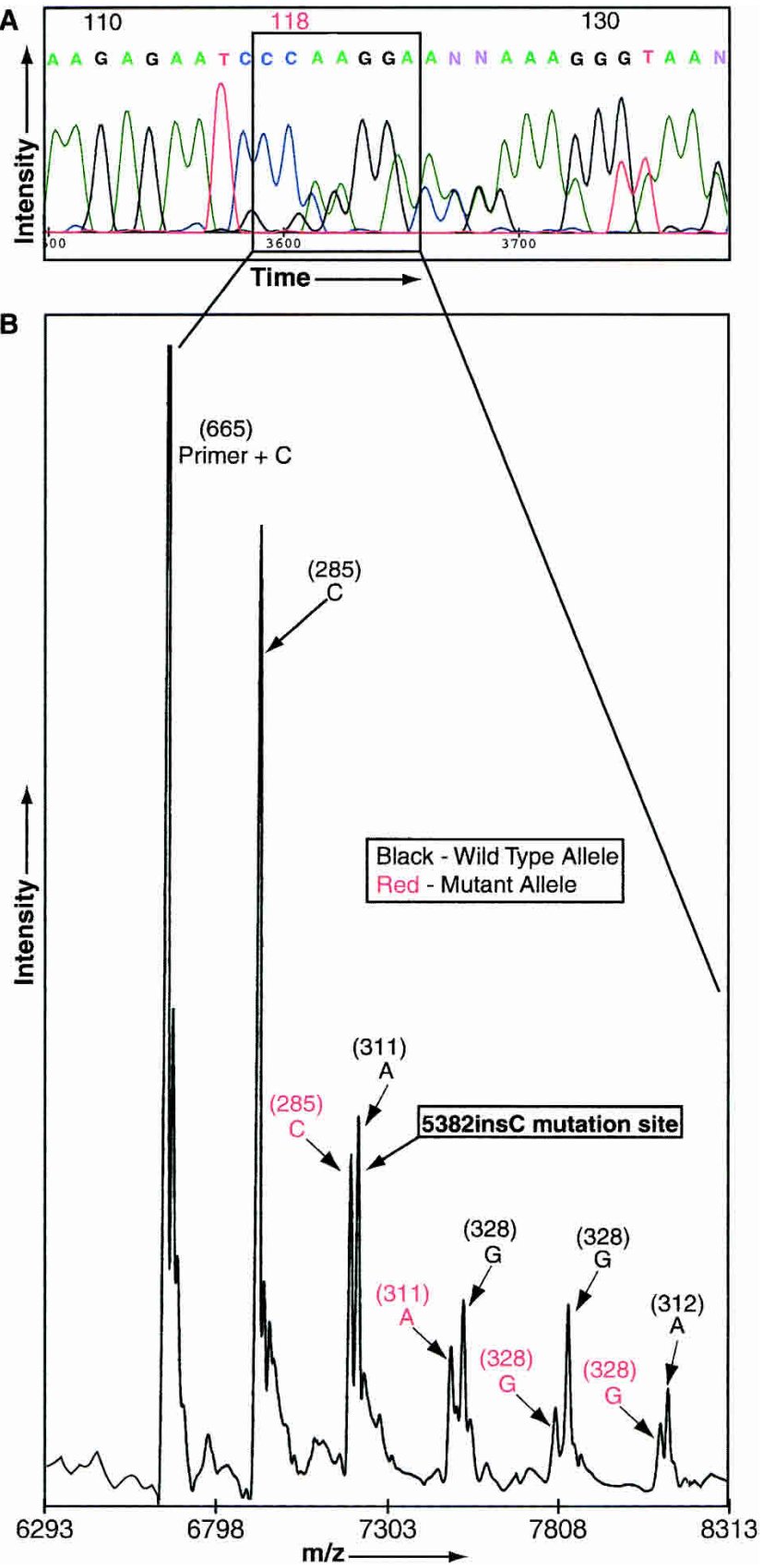

Figure 3 (A) Fluorescence electropherogram for a 5382ins C mutant. Peaks are clear before the mutation site and unintelligible beyond the mutation site (after " $\mathrm{C}$ " at position 118). (B) Mass spectrum showing the sequencing data for a 5382 ins $C$ mutant. The appearance of a succession of clear double peaks at and after the third position confirms the presence of the insertion of a " $\mathrm{C}$ ". The wild-type DNA sequence is 5 ' - . . CCAGGA$\ldots 3^{\prime}$, whereas the mutant DNA sequence is $5^{\prime}-\ldots$ CCCACG . . . $-3^{\prime}$.

toward developing this method into an automated, highthroughput mutation-detection technology.

\section{METHODS}

Primers for PCR and DNA sequencing were obtained from Midland, Inc. The PCR primers were designed by using the Primer3 oligonucleotide design software (Whitehead Institute) to produce DNA amplicons ranging in size from 300-500 bp. The same software was used to design DNA sequencing primers, about one to two basepairs away from the mutation site on the genomic DNA. Jumpstart Red Accutaq LA DNA polymerase, 3-hydroxypicolinic acid, and ammonium citrate were obtained from SigmaAldrich. Thermo Sequenase DNA polymerase and all four deoxyribonucleoside triphosphates (dNTPs) were obtained from Amersham Biosciences. Biotinylated dideoxyadenosine-5' triphosphate (biotin-11-ddATP), biotinylated dideoxycytidine5 -triphosphate (biotin-11-ddCTP), and biotinylated dideoxyguanidine-5'-triphosphate (biotin-11-ddGTP) were obtained from Perkin Elmer. Biotinylated dideoxyuridine-5' -triphosphate (biotin-16-ddUTP) was obtained from Enzo Life Sciences. Streptavidin-coated magnetic beads were obtained from Seradyn, Inc.

\section{PCR Amplification}

Human genomic DNA from anonymous donors with informed consent was used as a template for the PCR amplification of the regions of interest. We amplified the regions around exons 2 and 20 of the human BRCA1 gene, containing the frameshift Ashkenazi mutations $185 \mathrm{del} A G$ and 5382insC, respectively. The $20-\mu \mathrm{L}$ PCR reaction mixture contained 0.5 unit of Jumpstart Red Accutaq LA DNA polymerase, $1 \times$ Accutaq buffer (SigmaAldrich), 5 pmole each of forward and reverse primers (5'-GGAC GTTGTCATTAGTTCTTTGG-3', exon 2 forward; 5'-CGGACCA CAGGATTTGTGT-3', exon 2 reverse; 5'-ATATGACGTGTCTGC TCCAC-3', exon 20 forward; 5'-GGGAATCCAAATTACACAGC$3^{\prime}$, exon 20 reverse), 500 pmole dNTPs, and 100 ng DNA template. The reaction consisted of incubating the reaction mixture for $5 \mathrm{~min}$ at $96^{\circ} \mathrm{C}$, followed by 30 cycles for $30 \mathrm{sec}$ at $94^{\circ} \mathrm{C}, 30 \mathrm{sec}$ at $54^{\circ} \mathrm{C}$, and $2 \mathrm{~min}$ at $72^{\circ} \mathrm{C}$. The reaction mixture was then incubated for $15 \mathrm{~min}$ at $72^{\circ} \mathrm{C}$ to completely extend all partially extended or unextended fragments. The PCR product was purified from excess dNTPs and unextended primers by using an enzymatic digestion method as described previously (Kim et al. 2002).

\section{DNA Sequencing Using SPC Biotinylated Dideoxynucleotides and MALDI-TOF MS}

A $70-\mu \mathrm{L}$ reaction mixture contained 10 units of Thermo Sequenase DNA polymerase, $1 \times$ Thermo Sequenase reaction buffer, 60 pmole biotin-11-ddATP, 160 pmole biotin-11-ddCTP, 100 pmole biotin-11-ddGTP, 160 pmole biotin-16-ddUTP, 8 nmole dNTPs, 80 pmole sequencing primer (5'-ACTT ACCAGATGGGACAC-3', 185 delAG primer; 5'-CAAAGCGAG CAAGAG-AATC-3', 5382insC primer), and $2 \mu \mathrm{g}$ of the PCRamplified DNA template. The reaction consisted of 40 cycles for $20 \mathrm{sec}$ at $94^{\circ} \mathrm{C}$, for $30 \mathrm{sec}$ at $50^{\circ} \mathrm{C}$, and for $90 \mathrm{sec}$ at $60^{\circ} \mathrm{C}$. The above sequencing reaction products were purified from impurities such as unextended primer and false stops by streptavidincoated solid phase capture, desalted by using Zip Tip ${ }_{\mathrm{C} 18}$ (Millipore Corporation), and analyzed by MALDI-TOF MS as described previously (Edwards et al. 2001; Kim et al. 2002).

\section{DNA Sequencing Using a Fluorescent Capillary-Array DNA Sequencer}

A $20-\mu \mathrm{L}$ reaction mixture contained $100 \mathrm{ng}$ of the DNA template, 5 pmole of the sequencing primer (5'-CGGACCACAGGATTT GTGT-3', exon 2; 5'-ATATGACGTGTCTGCTCC-AC-3', exon 20), and $8 \mu \mathrm{L}$ of an ET Terminator mixture (Amersham Biosciences) containing DNA polymerase, fluorescence energy transfer dyelabeled ddNTPs, dNTPs, and reaction buffer. The reaction consisted of 30 cycles for $20 \mathrm{sec}$ at $94^{\circ} \mathrm{C}$, for $30 \mathrm{sec}$ at $54^{\circ} \mathrm{C}$, and for $1 \mathrm{~min}$ at $60^{\circ} \mathrm{C}$. The sequencing product was purified by isopropanol precipitation, washed with $70 \%$ ethanol, and then dried under vacuum. The dried sequencing product was resuspended in $8 \mu \mathrm{L}$ of MegaBACE loading solution (Amersham Biosciences) in a standard 96-well plate. The plate was loaded into a MegaBACE 1000 DNA sequencer (Amersham Biosciences), in which the DNA fragments were separated on the basis of their size by linear polyacrylamide gel electrophoresis and detected by using laserinduced fluorescence to produce a sequence electropherogram. 


\section{ACKNOWLEDGMENTS}

This work was supported by the Packard Fellowship for Science and Engineering (J.J.) and the Columbia University Genomics Initiative.

The publication costs of this article were defrayed in part by payment of page charges. This article must therefore be hereby marked "advertisement" in accordance with 18 USC section 1734 solely to indicate this fact.

\section{REFERENCES}

Andersen, P.S., Jespersgaard, C., Vuust, J., Christiansen, M., and Larsen, L.A. 2003. High-throughput single strand conformation polymorphism mutation detection by automated capillary array electrophoresis: Validation of the method. Human Mutat. 21: $116-122$.

Bowling, J.M., Bruner, K.L., Cmarik, J.L., and Tibbetts, C. 1991. Neighboring nucleotide interactions during DNA sequencing gel electrophoresis. Nucleic Acids Res. 19: 3089-3097.

Chen, X., Zehnbauer, B., Gnirke, A., and Kwok, P.-Y. 1997. Fluorescence energy transfer detection as a homogenous DNA diagnostic method. Proc. Natl. Acad. Sci. 94: 10756-10761.

Edwards, J.R., Itagaki, Y., and Ju, J. 2001. DNA sequencing using biotinylated dideoxynucleotides and mass spectrometry. Nucleic Acids Res. 29: e104.

Fakhrai-Rad, H., Pourmand, N., and Ronaghi, M. 2002. Pyrosequencing: An accurate detection platform for single nucleotide polymorphisms. Human Mutat. 19: 479-485.

Fei, Z., Ono, T., and Smith, L.M. 1998. MALDI-TOF mass spectrometric typing of single nucleotide polymorphisms with mass-tagged ddNTPs. Nucleic Acids Res. 26: 2827-2828.

Friedman, L.S., Ostermeyer, E.A., Szabo, C.I., Dowd, P., Lynch, E.D., Rowell, S.E., and King, M.-C. 1994. Confirmation of BRCA1 by analysis of germline mutations linked to breast and ovarian cancer in ten families. Nat. Genet. 8: 399-404.

Fu, D.J., Tang, K., Braun, A., Reuter, D., Darnhofer-Demar, B., Little, D.P., O'Donnell, M.J., Cantor, C.R., and Koster, H. 1998. Sequencing exons 5 to 8 of the p53 gene by MALDI-TOF mass spectrometry. Nat. Biotechnol. 16: 381-384.

Huang, X.C., Quesada, M.A., and Mathies, R.A. 1992. DNA sequencing using capillary array electrophoresis. Anal. Chem. 64: 2149-2154.

Ju, J., Ruan, C., Fuller, C.W., Glazer, A.N., and Mathies, R.A. 1995. Fluorescence energy transfer dye-labeled primers for DNA sequencing and analysis. Proc. Natl. Acad. Sci. 92: 4347-4351.

Kaetzke, A. and Eschrich, K. 2002. Simultaneous determination of different DNA sequences by mass spectrometric evaluation of Sanger sequencing reactions. Nucleic Acids Res. 30: e117.

Kim, S., Edwards, J.R., Deng, L., Chung, W., and Ju, J. 2002. Solid phase capturable dideoxynucleotides for multiplex genotyping using mass spectrometry. Nucleic Acids Res. 30: e85.

Kirpekar, F., Nordhoff, E., Larsen, L.K., Kristiansen, K., Roepstorff, P., and Hillenkamp, F. 1998. DNA sequence analysis by MALDI mass spectrometry. Nucleic Acids Res. 26: 2554-2559.

Kourkine, I.V., Hestekin, C.N., and Barron, A.E. 2002. Technical challenges in applying capillary electrophoresis-single strand conformation polymorphism for routine genetic analysis. Electrophoresis 23: 1375-1385.

Kyriacou, C.P. 2002. Single gene mutations in Drosophila: What can they tell us about the evolution of sexual behaviour? Genetica 116: $197-203$.

Li, J., Butler, J.M., Tan, Y., Lin, H., Royer, S., Ohler, L., Shaler, T.A., Hunter, J.M., Pollart, D.J., Monforte, J.A., et al. 1999. Single nucleotide polymorphism determination using primer extension and time-of-flight mass spectrometry. Electrophoresis 20: 1258-1265.

Pirmohamed, M. and Park, B.K. 2001. Genetic susceptibility to adverse drug reactions. Trends Pharmacol. Sci. 22: 298-305.

Prober, J., Trainor, G., Dam, R., Hobbs, F., Robertson, C., Zagursky. R., Cocuzza, A., Jensen, M., and Baumeister, K. 1987. A system for rapid DNA sequencing with fluorescent chain-terminating dideoxynucleotides. Science 238: 336-341.

Reynolds, R., Sensabaugh, G., and Blake E. 1991. Analysis of genetic markers in forensic DNA samples using the polymerase chain reaction. Anal. Chem. 63: 2-15.

Ronaghi, M., Uhlén, M., and Nyrén, P. 1998. A sequencing method based on real-time pyrophosphate. Science 281: 363-365.

Roses, A.D. 2000. Pharmacogenetics and the practice of medicine. Nature 405: $857-865$.

Roskey, M.T., Juhasz, P., Smirnov, I.P., Takach, E.J., Martin, S.A., and Haff, L.A. 1996. DNA sequencing by delayed extraction-matrix-assisted laser desorption/ionization time of flight mass spectrometry. Proc. Natl. Acad. Sci. 93: 4724-4729.

Ross, P., Hall, L., Smirnov, I., and Haff, L. 1998. High level multiplex genotyping by MALDI-TOF mass spectrometry. Nat. Biotechnol. 16: $1347-1351$.

Smith, L.M., Sanders, J.Z., Kaiser, R.J., Hughes, P., Dodd, C., Connell, C.R., Heiner, C., Kent, S.B.H., and Hood, L.E. 1986. Fluorescence detection in automated DNA sequencing analysis. Nature 321: 674-679.

Steele, R.J.C., Thompson, A.M., Hall, P.A., and Lane, D.P. 1998. The p53 tumour suppressor gene. Br. J. Surg. 85: 1460-1467.

Stickney, H.L., Schmutz, J., Woods, I.G., Holtzer, C.C., Dickson, M.C., Kelly, P.D., Myers, R.M., and Talbot, W.S. 2002. Rapid mapping of zebrafish mutations with SNPs and oligonucleotide microarrays. Genome Res. 12: 1929-1934.

Taranenko, N.I., Allman, S.L., Golovlev, V.V., Taranenko, N.V., Isola N.R., and Chen, C.H. 1998. Sequencing DNA using mass spectrometry for ladder detection. Nucleic Acids Res. 26: 2488-2490.

Tchernitchko, D., Lamoril, J., Puy, H., Robreau, A.M., Bogard, C., Rosipal, R., Gouya, L., Deybach, J.C., and Nordmann, Y. 1999. Evaluation of mutation screening by heteroduplex analysis in acute intermittent porphyria: Comparison with denaturing gradient gel electrophoresis. Clinica Chimica Acta 279: 133-143.

Received March 18, 2003; accepted in revised form November 24, 2003. 


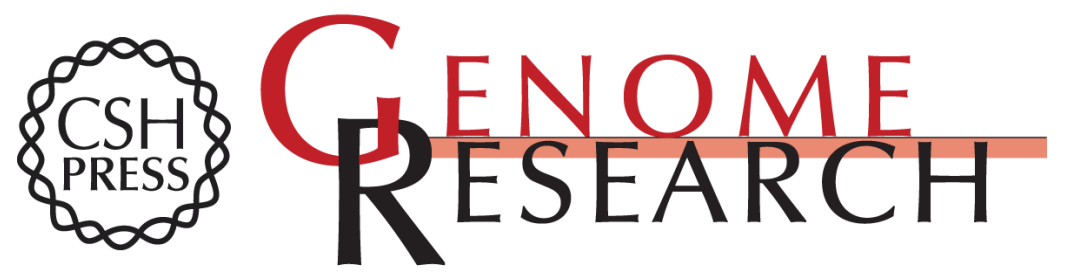

\section{Digital Detection of Genetic Mutations Using SPC-Sequencing}

Hameer Ruparel, Michael E. Ulz, Sobin Kim, et al.

Genome Res. 2004 14: 296-300

Access the most recent version at doi:10.1101/gr.1344104

References This article cites 28 articles, 6 of which can be accessed free at:

http://genome.cshlp.org/content/14/2/296.full.html\#ref-list-1

\section{License}

Email Alerting Receive free email alerts when new articles cite this article - sign up in the box at the Service top right corner of the article or click here.

\section{Affordable, Accurate Sequencing.}

To subscribe to Genome Research go to: https://genome.cshlp.org/subscriptions 